\title{
Nanoparticle Facilitated Extracellular Electron Transfer in Microbial Fuel Cells
}

\section{Citation}

Jiang, Xiaocheng, Jinsong Hu, Alexander M. Lieber, Charles S. Jackan, Justin C. Biffinger, Lisa A. Fitzgerald, Bradley R. Ringeisen, and Charles M. Lieber. 2014. "Nanoparticle Facilitated Extracellular Electron Transfer in Microbial Fuel Cells." In Nano Letters 14, no. 11: 6737-6742. doi:10.1021/nl503668q.

\section{Published Version}

doi:10.1021/nl503668q

\section{Permanent link}

http://nrs.harvard.edu/urn-3:HUL.InstRepos:22557427

\section{Terms of Use}

This article was downloaded from Harvard University's DASH repository, and is made available under the terms and conditions applicable to Open Access Policy Articles, as set forth at http:// nrs.harvard.edu/urn-3:HUL.InstRepos:dash.current.terms-of-use\#OAP

\section{Share Your Story}

The Harvard community has made this article openly available.

Please share how this access benefits you. Submit a story.

\section{Accessibility}




\title{
Nanoparticle Facilitated Extracellular Electron
}

\section{Transfer in Microbial Fuel Cells}

Xiaocheng Jiang, ${ }^{\dagger}$, Jinsong Hu ${ }^{\dagger}, \perp \S$ Alexander M. Lieber, ${ }^{\dagger}$ Charles S. Jackan, ${ }^{\dagger}$ Justin C.

Biffinger," Lisa A. Fitzgerald, "Bradley R. Ringeisen, " Charles M. Lieber ${ }^{*}+$, t

${ }^{\dagger}$ Department of Chemistry and Chemical Biology and ${ }^{\star}$ Division of Engineering and Applied Sciences, Harvard University, Cambridge, Massachusetts 02138, USA. ${ }^{\perp}$ CAS Key Laboratory of Molecular Nanostructure and Nanotechnology, Institute of Chemistry, Chinese Academy of Sciences, Beijing 100190, China. "Chemistry Division, US Naval Research Laboratory, 4555

Overlook Avenue, SW, Washington, DC 20375, USA.

$\S$ These authors contributed equally to this work.

\begin{abstract}
:
Microbial fuel cells (MFCs) have been the focus of substantial research interest due to their potential for long-term, renewable electrical power generation via the metabolism of a broad spectrum of organic substrates, although the low power densities have limited their applications to date. Here, we demonstrate the potential to improve the power extraction by exploiting biogenic inorganic nanoparticles to facilitate extracellular electron transfer in MFCs. Simultaneous shortcircuit current recording and optical imaging on a nanotechnology-enabled platform showed substantial current increase from Shewanella PV-4 after the formation of cell/iron sulfide nanoparticle aggregates. Detailed characterization of the structure and composition of the cell/nanoparticle interface reveals crystalline iron sulfide nanoparticles in intimate contact with and uniformly coating the cell membrane. In addition, studies designed to address the fundamental mechanisms of charge transport in this hybrid system showed that charge transport only occurred in
\end{abstract}


presence of live Shewanella, and moreover demonstrated that the enhanced current output can be attributed to improved electron transfer at cell/electrode interface and through the cellular-networks. Our approach of interconnecting and electrically contacting bacterial cells through biogenic nanoparticles represents a unique and promising direction in MFC research, and has the potential to not only advance our fundamental knowledge about electron transfer processes in these biological systems, but also overcome a key limitations in MFCs by constructing an electrically connected, three-dimensional cell network from the bottom-up.

Keywords: bacteria / facilitated electron transport / electrochemically active / iron sulfide / Shewanella 
MFCs are capable of harvesting electrical power directly from waste and renewable biomass, and thus represent a promising technology for sustainable energy production. ${ }^{1-5}$ Central to MFC technology is the unique capability of electrochemically active bacteria, such as Shewanella and Geobacter, to divert electrons from the oxidative metabolism of organic substrates to the fuel cell anode. ${ }^{2,3,6}$ This is a complex process that has been extensively investigated in several model systems, revealing a diversity of electron pathways including direct transfer through outermembrane proteins, ${ }^{7,8}$ mediated transfer through the excretion of soluble redox molecules, ${ }^{9-11}$ or long-range charge transport along filamentous pili. ${ }^{12-16}$ These evolutionarily developed strategies for extracellular electron transfer, however, have been found to be among the major limiting factors in the process of current production. ${ }^{17}$ For example, numerical modeling of the response of $G$. sulfurreducens biofilms cultured on a rotating disk electrode indicated that electron transport limits the respiration rate of the cells furthest from the electrode to the extent that cell division is not possible. ${ }^{18}$ Our recent work on single-bacterium level electrochemical studies also demonstrated that the current contribution from remote bacterial cells was significantly diminished at longer cellelectrode distances. ${ }^{19}$

Nanoscale materials and devices, such as metal/semiconductor nanoparticles, nanowires and carbon nanotubes, have been widely exploited to probe and interact with biological systems due to their comparable dimensions to biomolecules and unique electronic properties. ${ }^{20-28}$ In particular, rational integration of these nanomaterials in bioelectronics devices have been reported as a unique approach to facilitate the electron transfer at biological interfaces. ${ }^{23-28}$ For example, electron transfer was more efficient in amperometric biosensors and enzymatic biofuel cells with rationally incorporated gold nanoparticles, ${ }^{23,24}$ which allowed optimal alignment of the bioelectrocatalyst on the electrode surfaces and thus more intimate/direct coupling with active redox centers. In addition, dissimilatory intermembrane and intramembrane reduction of metals into nanoparticles has been well-documented $^{29,30}$ generating a unique opportunity to study a potential electrochemical connection between biotic and abiotic materials. ${ }^{31}$ The "doping" of Shewanella biofilms with iron 
oxide/sulfide nanoparticles ${ }^{32,33}$ or reduced graphene oxide nanosheets ${ }^{34,35}$ has also been reported to enhance the current output as a result of increased electrical conductivity of the bacterial network. The current work presents a detailed structural and electrochemical study of nanoparticle facilitated bacterial electron transfer in a model system Shewanella PV-4, using a nanotechnology enabled platform to probe charge transport at different length scales.

Biomineralized iron sulfide was employed for the current studies because of the importance of sulfur-mediated electron shuttling during bacterial iron reduction ${ }^{36}$ and the intriguing electronconducting properties of as-formed mackinawite nanoparticles. ${ }^{33}$ The experiments were carried out on the same nanoelectrode platform that we developed for single-microbe level electrochemical studies. ${ }^{11,37}$ In short, transparent Ti/Au electrode arrays with silicon nitride passivation layer were fabricated by photolithography, where $6 \mu \mathrm{m} \times 10 \mu \mathrm{m}$ windows were opened at the tip of each finger electrode by reactive ion etching. The electrochemical measurements were performed in a twoelectrode configuration given the small current levels, ${ }^{38,39}$ with $\mathrm{Ag} / \mathrm{AgCl}$ as both cathode and reference electrode. For in-situ generation of iron sulfide nanoparticles, $5 \mathrm{mM} \mathrm{FeCl} \mathrm{Fnd} \mathrm{Na}_{2} \mathrm{~S}_{2} \mathrm{O}_{3}$ were first added to the minimal media in the measurement chamber as iron and sulfur precursors respectively. ${ }^{33}$ Following the injection of a Shewanella culture, ${ }^{40}$ the recorded current shows an immediate increase to $\sim 9 \mathrm{pA}$ within the first 15 min (Figure 1a). Consistent with our previous results, this initial current change was independent of cell/electrode interaction, indicating mediated electron transfer as the dominant mechanism at the early stage. With the microbial reduction of $\mathrm{Fe}^{3+}$ and $\mathrm{S}_{2} \mathrm{O}_{3}{ }^{2-}$, the bacteria began to aggregate as a result of the biomineralization process, ${ }^{33}$ leading to the formation of large precipitates at $\sim 300 \mathrm{~min}$ (Figure 1b). The morphological change was accompanied by a steep increase in current to $~ 500$ pA (Figure 1a). This current level is 3-4 orders of magnitude higher than the reported values generated from single Shewanella or Geobacter cells, ${ }^{19,41}$ indicating that there is substantial contribution from remote bacterial cells that are not in direct contact with the exposed electrode. 

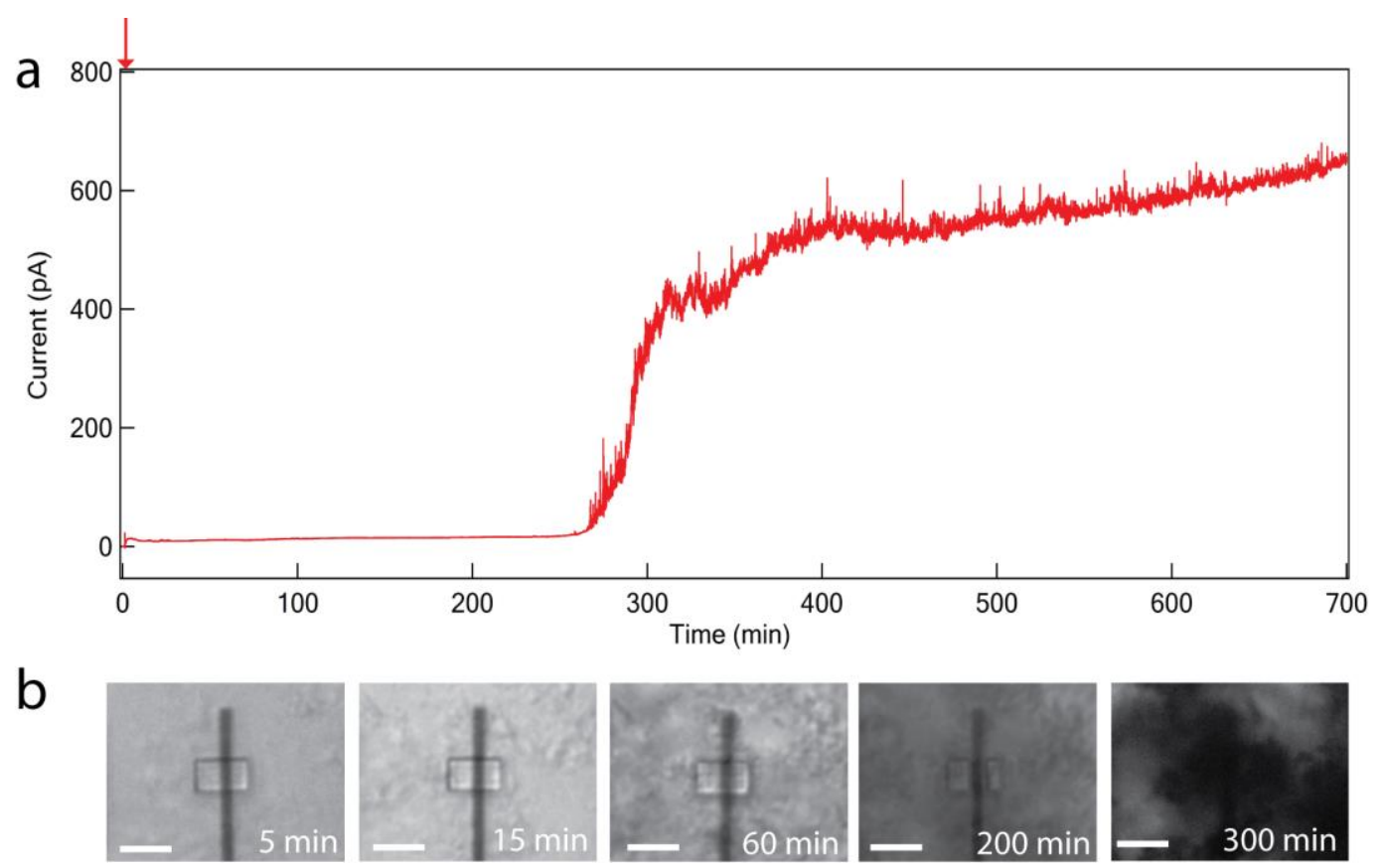

Figure 1. Current and cell morphology changes at early stage of measurement. (a) Short-circuit current recording from a nanoelectrode versus time in minutes. The red arrow indicates the injection of $0.5 \mathrm{~mL}$ cell culture. (b) Phase-contrast optical imaging of the electrode measured in (a) and surrounding area at specific time after cell injection. Scale bar, $10 \mu \mathrm{m}$.

Two additional control experiments were carried out at longer times to validate our hypothesis about the extracellular electron transfer in this hybrid system. First, a decrease of recorded current was noticed at $\sim 20 \mathrm{~h}$ as a result of nutrient (lactate) depletion over time. Injection of fresh, $\mathrm{N}_{2}$ purged lactate yielded an immediate recovery of current, thus confirming that the measured current output is directly associated with bacterial metabolism (Figure 2a). In addition, introduction of a biocide ( $0.1 \%$ glutaraldehyde) in a similar independent experiment (Figure S1) led to a drop of the current to $\sim 0$ within 50 minutes, thus showing that live bacteria are required for current production. Second, after a stable current level was achieved at $\sim 2500 \mathrm{~min}$, the original supernatant was carefully removed from the measurement chamber and replaced with fresh, $\mathrm{N}_{2}$ purged medium. This flush experiment induced almost no change in current amplitude (Figure 2b), demonstrating that the contribution from solution redox species is negligible. We attribute the suppression of solution mediated process and enhancement of direct electron transfer to the in-situ 
generation of iron sulfide nanoparticles, which not only improves the overall conductivity of the bacterial network by electrically interconnecting adjacent cells, but also modifies the cellular interfaces to make the bacteria-to-anode charge transport more efficient.
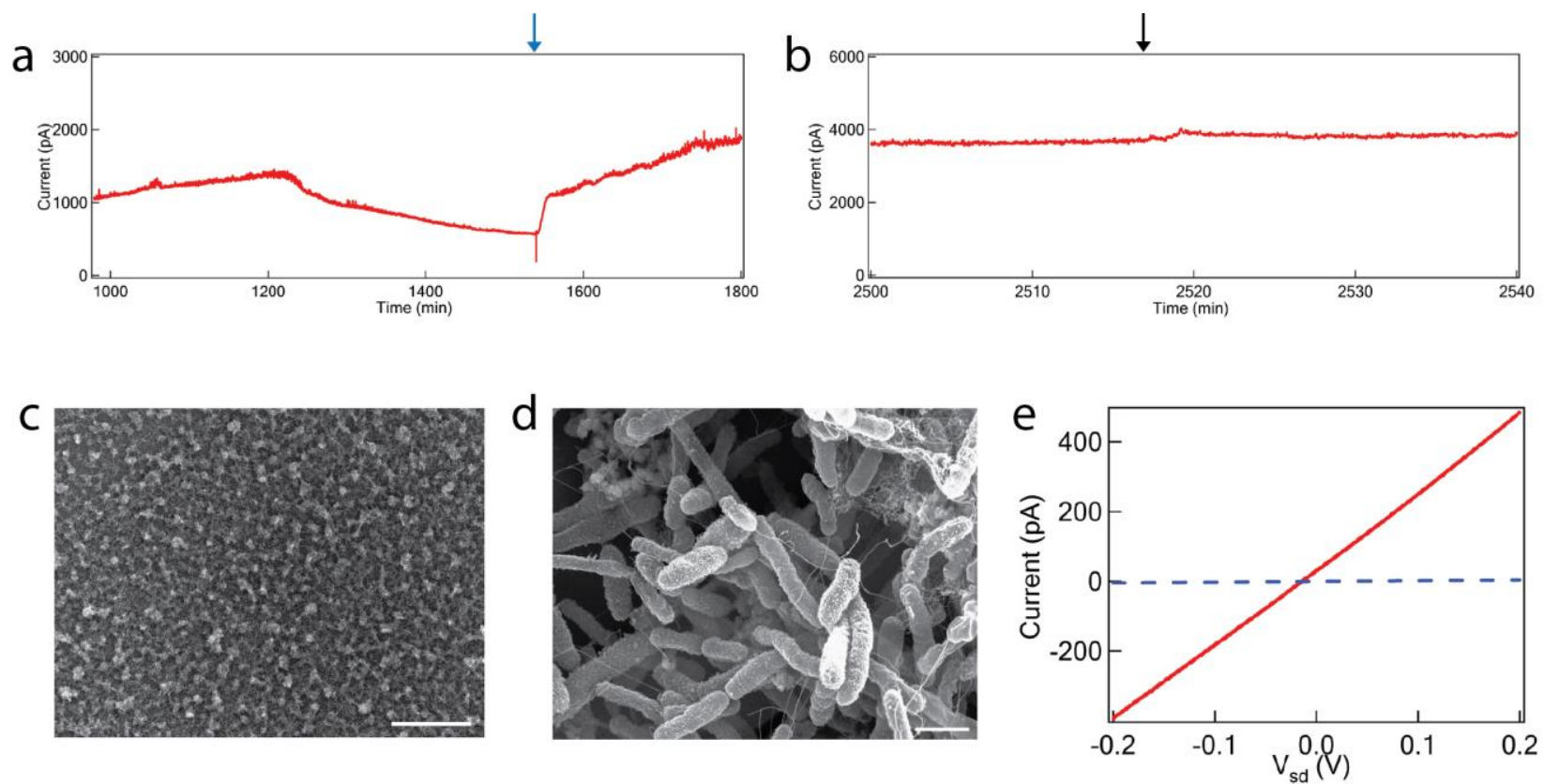

Figure 2. Characterization of the cell/nanoparticle hybrid system following biofilm formation. (a) The short-circuit current change with nutrient depletion and addition. The injection of lactate is marked by the blue arrow. (b) The effect of fresh media flush on current production. The removal of supernatant and addition of $\mathrm{N}_{2}$ purged medium is marked by the black arrow. (c, d) Low- and highmagnification SEM images of cell/nanoparticle aggregates formed after 2550 min of MFC operation. Scale bars, 100 and $1 \mu \mathrm{m}$, respectively. (e) Current vs. voltage measurement of cell/nanoparticle aggregate (red) and pure Shewanella biofilms (blue). Two on-chip microelectrodes (interspacing: $1 \mathrm{~mm}$ ) were used as two electrodes in these measurements.

Scanning electron microscopy (SEM) characterization ${ }^{42}$ of the precipitates following 2550 min of MFC operation revealed the formation of 10-20 $\mu \mathrm{m}$ sized cell/nanoparticle aggregates over the whole chip (Figure 2c), with each aggregate composed of hundreds of bacterial cells interconnected through nanoparticles and pili (Figure 2d). The electrical property of the cell/nanoparticle aggregate was investigated by a two-probe measurement, with two on-chip 
microelectrodes as source and drain electrodes, respectively (Figure 2e). The current vs. voltage curve has a linear shape consistent with ohmic-like contact at the cell/electrode interface (Figure 2e, red curve). The measured conductance of the hybrid system, $\sim 2.2 \mathrm{nS}$, is $>100$ fold higher than Shewanella biofilm alone (Figure 2e, blue curve). While more systematic electrical characterizations, such as four-probe or frequency-dependent measurement, will be required in the future to illuminate detailed nature of transport, our preliminary results clearly show the advantage of incorporating semiconductor nanoparticles to enhance the intrinsic extracellular electron transfer in biological systems.

In addition, we carried out transmission electron microscopy (TEM) imaging studies on fixed cell samples to investigate the detailed structure and composition of the cell/nanoparticle interface. The samples were prepared after $2550 \mathrm{~min}$ of cell operation by critical point drying. ${ }^{42}$ Low-resolution TEM images revealed a rough membrane surface with high-density plate-like structures (Figure 3a, b), which are consistent with high-resolution SEM observations of the cell morphology in Figure 2d. Significantly, higher-resolution TEM images show crystalline nanoparticles of 5-10 $\mathrm{nm}$ size in intimate contact with the cell membrane (Figure 3c). The measured lattice spacing, $\sim 3.1 \AA$, corresponds well to the (101) planes for mackinawite phase of iron sulfide. $^{33,43}$ The interaction between bacteria and nanoparticles could be through direct electron contact with outer-membrane cytochromes or indirect with reduced organic mediators like FAD. ${ }^{44}$ Either mechanism is critical to achieving efficient electrical coupling between redox-active membrane proteins and nanoparticles on the surface of Shewanella. In addition, composition analysis was carried out with energy-dispersive X-ray spectroscopy (EDX), yielding a Fe to $\mathrm{S}$ atomic ratio of 1.1 (Figure 3d). Two-dimensional EDX mapping was performed to further characterize the distribution of different elements. While carbon/oxygen was uniformly distributed over the entire cell body and phosphor (from phospholipids and intracellular genetic materials) was mainly detected inside of cell wall, iron and sulfur elements were exclusively located around the 
outer cell membrane (Figure 3e), serving as a porous semiconducting "shell" to facilitate the charge transport at bacteria/electrode or bacteria/bacteria interfaces.
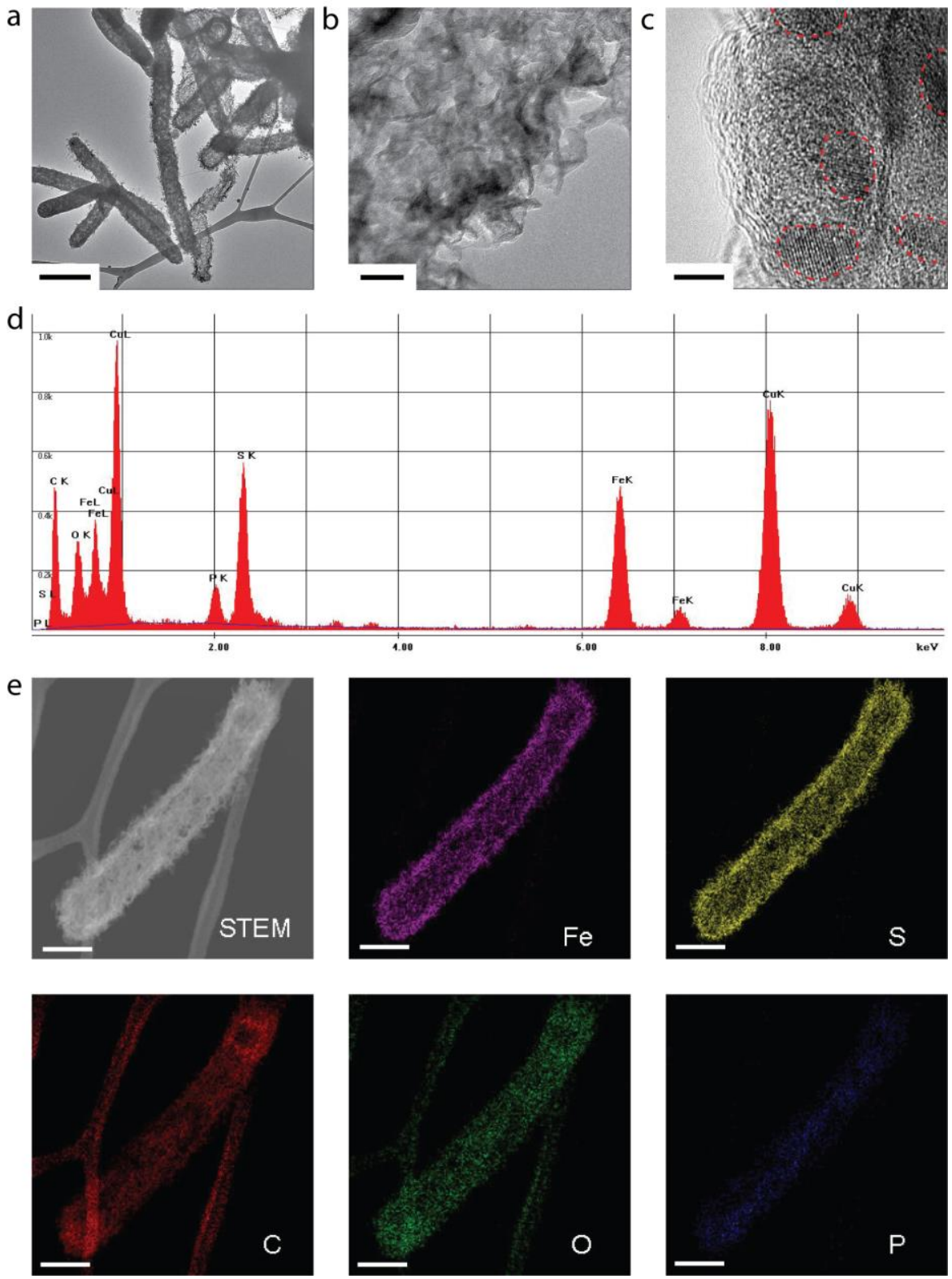

Figure 3. Structural and elemental analysis of cell/nanoparticle hybrid structures. (a-c) Low- and high-resolution TEM images of cell/nanoparticle interfaces. Scale bars, $1 \mu \mathrm{m}, 50 \mathrm{~nm}$ and $5 \mathrm{~nm}$. (d) EDX compositional analysis of the cell/nanoparticle aggregate. (e) Bright-field STEM image and corresponding EDX elemental mapping of a PV-4 cell coated with nanoparticles. Scale bar, $500 \mathrm{~nm}$.

Last, we examined electron transfer in our system following disruption of the majority of cell-cell interconnections by high shear-stress flow. ${ }^{45}$ Optical images show that most of the cell/nanoparticle aggregates formed on the chip during cell operation, except those tightly bound to 
the exposed electrodes, were removed during the flow (Figure 4a). Significantly, simultaneous measurements of electrode current show a three-order of magnitude decrease from ca. 8 nA to 10 pA (Figure 4b). This result is consistent with nanoparticle mediated electron transfer from the cell and validates the important contribution of remote bacterial cells through nanoparticle-mediated long-range charge transport. ${ }^{33}$ After the flow was stopped, optical imaging showed that small clusters of cells could aggregate on electrodes (Figure 4c, right), and simultaneous current measurements demonstrated concomitant current increases from $\sim 10 \mathrm{pA}$ to $\sim 30 \mathrm{pA}$ correlated with this cell/electrode interaction. The current increases were accompanied by a large number of spikes that we suggest are due to nonoptimal interaction between the cell aggregate and electrode surface when the electrical contact was being established. Overall, these results provide unambiguous evidence for the direct electron transfer mechanism in this hybrid system, and further demonstrate the importance of iron sulfide nanoparticles in achieving electrically favorable cell/electrode and cell/cell electron transport.

a
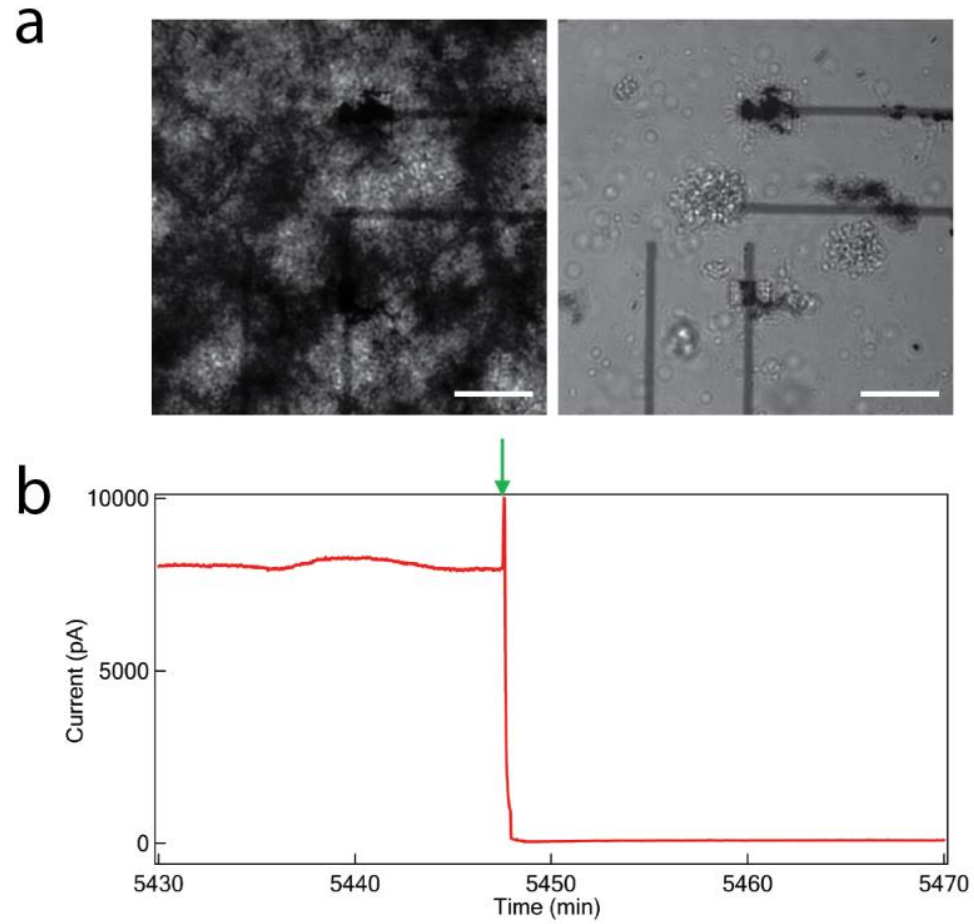

C
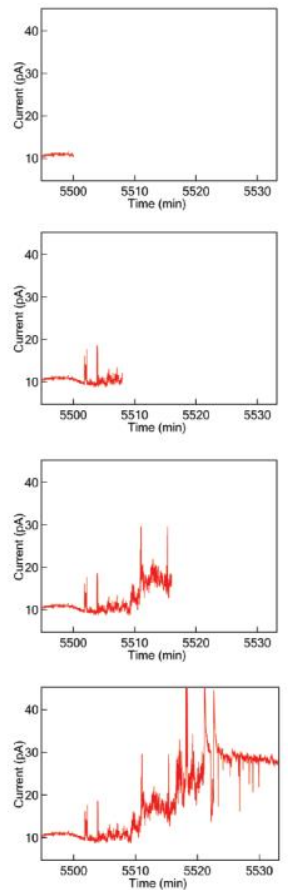
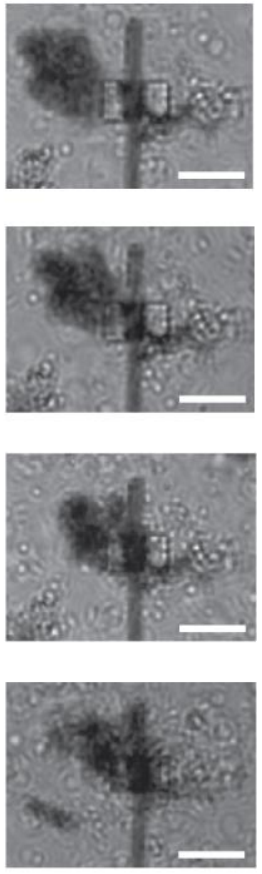

Figure 4. (a) Phase-contrast imaging of cells and electrodes before (left) and after (right) a high shear-stress flush was applied by repetitive extracting and refilling the supernatant at $100 \mu \mathrm{L} / \mathrm{s} \quad{ }^{45}$ 
Scale bar, $20 \mu \mathrm{m}$. (b) Concomitant short-circuit current recording before and after the high-shear stress flush (indicated by green arrow) applied to the measurement chip. (c) Simultaneous current recording and optical imaging when a cell/nanoparticle aggregate approached and became attached to an electrode. Scale bar, $10 \mu \mathrm{m}$.

In summary, we have shown that biogenic nanoparticles can serve as "bridges" to facilitate efficient extracellular electron transfer from Shewanella cells to electrode surfaces and also between interconnected cell networks. Simultaneous short-circuit current measurements and optical imaging demonstrated a substantial current increase after the formation of cell/nanoparticle aggregates. Detailed structural characterization of cell/nanoparticle interface reveals crystalline iron sulfide nanoparticles in intimate contact with and uniformly coating the cell membrane. Studies of fundamental mechanisms of charge transport showed that charge transport required live bacteria, and moreover, demonstrated that the enhanced current output was due to improved electron transfer at both cell/electrode interface and within the extended cellular-networks. Our current approach of interconnecting and electrically contacting bacterial cells through rationally designed/synthesized nanoparticles represents a unique and promising direction in MFC research, and has the potential to not only advance our fundamental knowledge about electron transfer processes in biological systems, but also overcome a key limitations in MFCs by constructing an electrically connected, three-dimensional cell network from the bottom-up.

\section{AUTHOR INFORMATION}

Corresponding Author. *E-mail: cml@,cmliris.harvard.edu

ACKNOWLEDGMENTS. C.M.L. and B.R.R. acknowledge support of this work by the Air Force Office of Scientific Research and J.C.B and L.A.F. acknowledge ONR/NRL Nanoscience Institute BLK 6.1 funding. 
NOTES. The authors declare no competing financial interest" at end of manuscript 


\section{References and Notes}

(1) Logan, B. E.; Regan, J. M. Environ. Sci. Technol. 2006, 40, 5172-5180.

(2) Lovley, D. R. Nat. Rev. Microbiol. 2006, 4, 497-508.

(3) Logan, B. E. Nat. Rev. Microbiol. 2009, 7, 375-381.

(4) Logan, B. E.; Rabaey, K. Science 2012, 337, 686-690.

(5) Rabaey, K.; Verstraete, W. Trends Biotechnol. 2005, 23, 291-298.

(6) Bond, D. R.; Holmes, D. E.; Tender, L. M.; Lovley, D. R. Science 2002, 295, 483-485.

(7) Hartshorne, R. S.; Reardon, C. L.; Ross, D.; Nuester, J.; Clarke, T. A.; Gates, A. J; Mills, P. C.; Fredrickson, J. K.; Zachara, J. M.; Shi, L.; Beliaev, A. S.; Marshall, M. J.; Tien, M.; Brantley, S.; Butt, J. N.; Richardson, D. J. Proc. Natl. Acad. Sci. U. S. A. 2009, 106, 2216922174.

(8) Chaudhuri, S. K.; Lovley, D. R. Nat. Biotechnol. 2003, 21, 1229-1232.

(9) Newman, D. K.; Kolter, R. Nature 2000, 405, 94-97.

(10) Marsili, E.; Baron, D. B.; Shikhare, I. D.; Coursolle, D.; Gralnick, J. A.; Bond, D. R. Proc. Natl. Acad. Sci. U. S. A. 2008, 105, 3968-3973.

(11) Jiang, X.; Hu, J.; Fitzgerald, L. A.; Biffinger, J. C.; Xie, P.; Ringeisen, B. R.; Lieber, C. M. Proc. Natl. Acad. Sci. U. S. A. 2010, 107, 16806-16810.

(12) Gorby, Y. A.; Yanina, S.; McLean, J. S.; Rosso, K. M.; Moyles, D.; Dohnalkova, A.; Beveridge, T. J.; Chang, I. S.; Kim, B. H.; Kim, K. S.; Culley, D. E.; Reed, S. B.; Romine, M. F.; Saffarini, D. A.; Hill, E. A.; Shi, L.; Elias, D. A.; Kennedy, D. W.; Pinchuk, G.; Watanabe, K.; Ishii, S.; Logan, B.; Nealson, K. H.; Fredrickson, J. K. Proc. Natl. Acad. Sci. U. S. A. 2006, 103, 11358-11363.

(13) G. Reguera; McCarthy, K. D.; Mehta, T.; Nicoll, J. S.; Tuominen, M. T.; Lovley, D. R. Nature 2005, 435, 1098-1101.

(14) El-Naggar, M. Y.; Wanger, G.; Leung, K. M.; Yuzvinsky, T. D.; Southam, G.; Yang, J.; Lau, W. M.; Nealson, K. H. Proc. Natl. Acad. Sci. U. S. A. 2010, 107, 18127-18131. 
(15) Malvankar, N. S.; Vargas, M.; Nevin, K. P.; Franks, A. E.; Leang, C.; Kim, B. C.; Inoue, K.; Mester, T.; Covalla, S. F.; Johnson, J. P.; Rotello, V. M.; Tuominen, M. T.; Lovley, D. R. Nat. Nanotech. 2011, 6, 573-579.

(16) Breuer, M.; Rosso, K. M.; Blumberger, J. Proc. Natl. Acad. Sci. U. S. A. 2014, 111, 611616.

(17) Schröder, U. Phys. Chem. Chem. Phys. 2007, 9, 2619-2629.

(18) Bonanni, P. S.; Bradley, D. F.; Schrott, G. D.; Busalmen, J. P. ChemSusChem 2013, 6, 711720.

(19) Jiang, X. C.; Hu, J. S.; Petersen, E. R.; Fitzgerald, L. A.; Jackan, C. S.; Lieber, A. M.; Ringeisen, B. R.; Lieber, C. M.; Biffinger, J. C. Nat. Comm. 2013, 4, 2751.

(20) Duan, X.; Fu, T. M.; Liu; J.; Lieber, C.M. Nano Today 2013, 8, 351-373.

(21) Tian, B.; Cohen-Karni, T.; Qing, Q.; Duan, X.; Xie, P.; Lieber, C. M. Science 2010, 329, 831-834.

(22) Tian B.; Lieber, C. M. Annu. Rev. Anal. Chem. 2013, 6, 31-51.

(23) Katz, E.; Willner, I. Angew. Chem. Int. Ed. 2004, 43, 6042-6108.

(24) Xiao,Y.; Patolsky, F.; Katz, E.; Hainfeld, J. F.; Willner, I. Science 2003, 299, 1877-1881.

(25) Patolsky, F.; Weizmann, Y.; Willner, I. Angew. Chem. Int. Ed. 2004, 43, 2113-2117.

(26) Gooding, J. J.; Wibowo, R.; Liu, J. Q.; Yang, W. R.; Losic, D.; Orbons, S.; Mearns, F. J.; Shapter, J. G.; Hibbert, D. B. J. Am. Chem. Soc. 2003, 125, 9006-9007.

(27) Qian, F.; Wang, H.; Ling, Y.; Wang, G.; Thelen, M. P.; Li, Y. Nano Lett. 2014, 14, 36883693.

(28) Ding, C. M.; Liu, H.; Zhu, Y.; Wan, M. X.; Jiang, L. Energy Environ. Sci. 2012, 5, 85178522.

(29) Crookes-Goodson, W. J.; Slocika, J. M.; Naik, R. R. Chem. Rev. Soc. 2008, 37, 2403-2412.

(30) Nealson, K. H.; Belz, A.; McKee, B. Antoine van Leeuwenhoek 2002, 81, 215-222. 
(31) Richardson, D. J.; Butt, J. N.; Fredrickson, J. K.; Zachara, J. M.; Shi, L.; Edwards, M. J.;

White, G.; Baiden, N.; Gates, A. J.; Marritt, S. J.; Clarke, T. A. Mol. Microbiol. 2012, 85, 201-212.

(32) Nakamura, R.; Kai, F.; Okamoto, A.; Newton, G. J.; Hashimoto, K. Angew. Chem. Int. Ed. 2009, 48, 508-511.

(33) Nakamura, R.; Okamoto, A.; Tajima, N.; Newton, G. J.; Kai, F.; Takashima, T.; Hashimoto, K. Chem. Bio. Chem. 2010, 11, 643-645.

(34) Yong, Y. C; Yu, Y. Y.; Zhang, X.; Song. H. Angew. Chem. Int. Ed. 2014, 53, 4480-4483.

(35) Wang, H.; Wang, G.; Ling, Y.; Qian, F.; Song, Y.; Lu, X.; Chen, S.; Tong, Y.; Li, Y. Nanoscale, 2013, 5, 10283-10290.

(36) Flynn, T. M.; O’Loughlin, E. J.; Mishra, B.; DiChristina, T. J.; Kemner, K. M. Science, 2014, 344, 1039-1042.

(37) The transparent nanoelectrodes were fabricated on glass slides using standard photolithography techniques. Glass substrates $(50 \times 22 \mathrm{~mm}, 0.17 \mathrm{~mm}$ thick; VWR $)$ were cleaned in Piranha solution (3:1 concentrated sulfuric acid to $30 \%$ hydrogen peroxide) for 30 min, rinsed with deionized (DI) water (15s), acetone (15s), isopropanol (15s), and dried in $\mathrm{N}_{2}$ flow. A two-layer photoresist consisting of LOR3A and S1805 (Microchem) was sequentially deposited by spin-coating, and baked for $5 \mathrm{~min}$ at 185 and $115^{\circ} \mathrm{C}$ respectively. The metal electrodes were defined by photolithography, followed by thermal evaporation of $2 \mathrm{~nm} \mathrm{Ti}$ and $8 \mathrm{~nm} \mathrm{Au} ; 1 \mathrm{~nm}$ Ti was evaporated on top of Au as an adhesion layer in cases where $\mathrm{Si}_{3} \mathrm{~N}_{4}$ was used for passivation. Each glass chip has 48 finger electrodes $(2 \mu \mathrm{m}$ wide, $25 \mu \mathrm{m}$ spacing) defined at the chip center with fan out wiring to I/O points at the two ends of the chip. The finger electrodes were arranged in four groups of 12 parallel electrodes placed with their ends on the sides of a $500 \mu \mathrm{m}$ x $500 \mu \mathrm{m}$ square at the chip center. After lift-off, plasma enhanced chemical vapor deposition (PECVD) was used to deposit $\sim 400 \mathrm{~nm}$ 
$\mathrm{Si}_{3} \mathrm{~N}_{4}$ over the entire chip. PMMA was then coated on the chip and e-beam lithography was used to define rectangular openings $(6 \mu \mathrm{m} \times 10 \mu \mathrm{m})$ at the tips for access to the electrodes. Anisotropic reactive ion etching (RIE, $50 \mathrm{sccm} \mathrm{CHF}_{3}, 30 \mathrm{sccm} \mathrm{H}_{2}, 3$ mTorr, $75 \mathrm{~W}, 3$ min) was used to remove $\mathrm{Si}_{3} \mathrm{~N}_{4}$ in the patterned regions. Last, the electrodes were cleaned by $1 \mathrm{M}$ sulfuric acid followed by UV ozone at $200{ }^{\circ} \mathrm{C}$ for $2 \mathrm{~min}$.

(38) Hoeben, F. J. M.; Meijer, F. S.; Dekker, C.; Albracht, S. P. J.; Heering, H. A.; Lemay, S. G. ACS Nano 2008, 2, 2497-2504.

(39) Heinze, J. Angew. Chem. Int. Ed. 1993, 32, 1268-1288.

(40) Shewanella loihica PV-4 were grown from $-80{ }^{\circ} \mathrm{C}$ glycerol stock cultures by inoculating 50 $\mathrm{mL}$ of Luria-Bertani (LB) broth (Sigma-Aldrich) with gentle shaking (100 rpm) in air for approximately $48 \mathrm{~h}$ at $25^{\circ} \mathrm{C}$. The LB culture was then centrifuged at $3000 \mathrm{rpm}$ for $5 \mathrm{~min}$ to remove the supernatant. The cells were washed and re-dispersed with minimal media (MM) containing $30 \mathrm{mM}$ sodium lactate. The formulation of MM was reported previously (12). The re-dispersed culture was shaken $(100 \mathrm{rpm})$ in air for $18 \mathrm{hr}$ at $25{ }^{\circ} \mathrm{C}$ before cell measurements.

(41) Liu, H.; Newton, G. J.; Nakamura, R.; Hashimoto, K.; Nakanishi, S. Angew. Chem. Int. Ed. 2010, 49, 6596-6599.

(42) Samples for electron microscopy studies were prepared as follows: The cell/nanoparticle aggregates on the measurement chip were fixed with $2 \%$ glutaraldehyde for 2 hours, rinsed with DI water 3 times, and gradually dehydrated in a graded series of ethanol $(25 \%, 50 \%$. $75 \%, 90 \%, 95 \%, 100 \%, 15 \mathrm{~min}$ each). The sample in $100 \%$ ethanol was then collected and placed in a critical point dryer (Tousimis Autosamdri-815), purged with liquid $\mathrm{CO}_{2}$ for 10 min, and subject to critical point drying before SEM (Zeiss Ultra 55) and TEM/EDX (JEOL 2010 FEG) measurements.

(43) Rickard, D.; Luther, G. W. Chem. Rev. 2007, 107, 514-562. 
(44) von Canstein, H.; Ogawa, J.; Shimizu, S.; Lloyd, J. R. Appl. Environ. Microbiol. 2007, 74, 615-623.

(45) High shear-stress fluid flow was applied locally to the measurement region by extracting and refilling the supernatant 5 times using $1 \mathrm{~mL}$ syringe at a flow rate of $100 \mu \mathrm{L} / \mathrm{s}$. 
Table of Contents Graphic
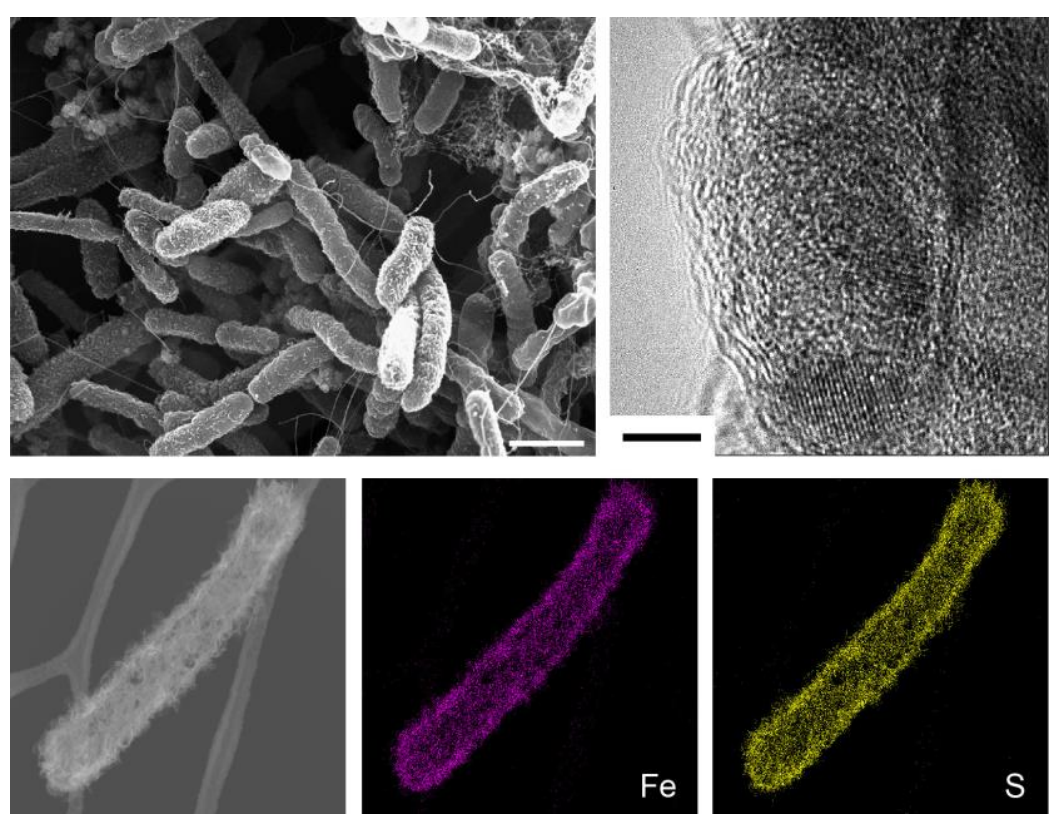


\section{Supporting Information}

\section{Nanoparticle Facilitated Extracellular Electron Transfer in Microbial Fuel Cells}

Xiaocheng Jiang, Jinsong Hu, Alexander M. Lieber, Charles S. Jackan, Justin C. Biffinger, Lisa

A. Fitzgerald, Bradley R. Ringeisen, and Charles M. Lieber

Corresponding author E-mail: cml@cmliris.harvard.edu

This file includes:

Supplementary Figure S1 


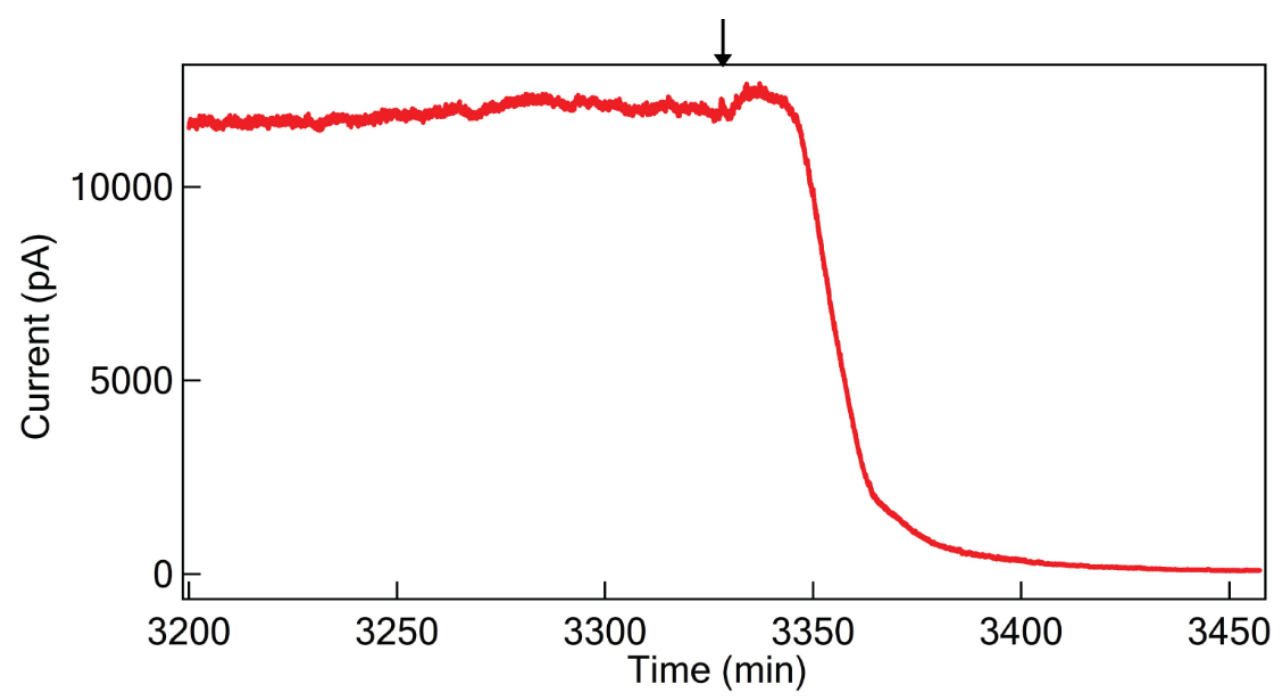

Figure S1 Short-circuit current recording when $0.1 \%$ glutaraldehyde was applied to the measurement chamber as a biocide. The current generation was completely quenched within 50 min after biocide addition, which further verified that the measured current was directly associated with the bacterial metabolism. 